\title{
Transient Stability Augmentation of the Algerian South-Eastern Power System including PV Systems and STATCOM
}

\author{
Boubekeur Bouhadouza \\ Department of Electrical Engineering \\ Faculty of Technology \\ Ferhat Abbas University Setif I \\ Setif, Algeria \\ bouhadouzaboubekeur@gmail.com
}

\author{
Tarek Bouktir \\ Department of Electrical Engineering \\ Faculty of Technology \\ Ferhat Abbas University Setif I \\ Setif, Algeria \\ tbouktir@gmail.com
}

\author{
Adnane Bourenane \\ Electrical Engineering Department \\ Faculty of Applied Science \\ University of Ouargla \\ Ouargla, Algeria \\ adnanebourenanehmd@gmail.com
}

\begin{abstract}
The transient stability of the 12-bus Algerian southeast power system is studied in this paper. This electrical system has abundant reactive power due to the long transmission lines and generators' voltage. This capacitive power increases bus voltage which leads to network instability. The use of conventional compensators does not provide adequate and fast solutions. FACTS technology improves the efficiency of these compensators in solving the problem of power system instability efficiently. Among its elements, a synchronous compensator STATCOM control is proposed to decrease bus overvoltage and damping oscillations. Disturbance at bus B-1 is taken into consideration. This disturbance represents the photovoltaic (PV) array which exploits the abundantly available solar irradiation in the desert of Algeria. Various simulation tests have been carried out using NEPLAN software and the proposed design algorithms are proved in the relevant discussion.
\end{abstract}

Keywords-FACTS; transient stability; photovoltaic; STATCOM; NEPLAN; overvoltage

\section{INTRODUCTION}

Nowadays, power networks include renewable energy sources like wind generators, solar energy panels, and hydropower systems. However, the occurrence of faults causes the instability of the grid-connected energy sources. It is proven that the transient stability involves the determination of whether or not synchronism is maintained after the system has been subjected to severe disturbances like a sudden application of load, loss of generation, loss of large load, or a fault [1-4]. Solar energy is freely available and pollution-free when compared to fossil fuels. Photovoltaic (PV) panels are utilized to convert sun irradiation to electric energy. The output voltage of a solar panel is varying depending on sun's irradiation and temperature. The increase of PV generation leads to the reduction of the generation capacity of conventional synchronous generators. Authors in [5] analyzed the transient stability of a PV system taking into account the shading effects on the IEEE9-bus system model. Authors in [6] discussed about determining the impact of voltage on the reactive power of a PV inverter. Authors in [7] discussed the impact of a gridconnected PV generator on the dynamic voltage stability of the
IEEE-13 bus power system with solar intermittency, PV penetration level, line outage, and load increase. Authors in [8] explained the assessment and impact of large scale gridconnected PV systems on the transient stability of a power system with and without infinite bus. This impact became more serious when some PV systems were disconnected simultaneously during voltage sags.

The use of FACTS (Flexible AC Transmission Systems) devices at strategic locations with well-designed controllers can help improving the operational efficiency of power systems. Among FACTS devices, the Static Synchronous Compensator (STATCOM) is of a particular interest, because it is able to improve the transfer capability of a power system by improving voltage regulation and stability. It can significantly provide smooth and rapid reactive compensation for voltage support. It also enhances power oscillation damping and transient stability [9-11]. Authors in [2] studied the optimum location and parameters of STATCOM in order to minimize system power loss and to enhance the security of the power system network. Authors in [13-14] presented the effect of STATCOM in improving the transient stability condition, and studied the effect of placing the controller at various locations on system stability.

This paper discusses ways to improve the transient stability of a 12-bus power system considering an about $1 \mathrm{pu}$ voltage amplitude decrease at most buses. The study is performed on a model of the Algerian south-eastern 12-bus system. Because of the lengthy transmission lines, there is an excess of capacitive power which causes voltage amplitudes to exceed unity. Adding an inductance is insufficient in this case. Parallel FACTS compensators are necessary to regulate bus voltage and to damp power system oscillations. STATCOMs are one solution to regulate over-voltage and improve transient stability when a system is subject to a contingency. Large scale PVs are added to help the power plant in the test system. Two dynamic models are considered for load flow test and transient stability test. The ability of a power system to maintain stability after a large disturbance is investigated with and without STATCOM. The NEPLAN version 5.5.5 software was used as a simulation 
platform. The characteristics of the hardware used for the simulation are: Intel (R) Core(TM) i7-4700MQ CPU, $2.4 \mathrm{GHz}$ (8 CPUs), 8GB RAM.

\section{POWER SYSTEM MODEL}

\section{A. Synchronous Machine Model}

In this paper, the two axis model is used to represent the synchronous machines. The fourth order differential equations of the synchronous machines are expressed as in [15]:

$$
\begin{gathered}
\frac{d \delta_{i}}{d t}=\mathrm{w}_{\mathrm{i}}-w_{s} \\
\frac{d w_{i}}{d t}=\frac{1}{w_{i}}\left[P_{m i}-\left(E_{q i}^{\prime}-X_{d i}^{\prime} I_{d i}\right) I_{d i}-\left(E_{d i}^{\prime}+X_{q i}^{\prime} I_{q i}\right)-\right. \\
D_{d i}\left(w_{i}-w_{s}\right) \\
\frac{d E_{q i}^{\prime}}{d t}=\frac{1}{T_{d i}^{\prime}}\left[E_{f d i}-E_{f d i}^{\prime}-\left(X_{d i}-X_{d i}^{\prime}\right) I_{d i}\right] \\
\frac{d E_{d i}^{\prime}}{d t}=\frac{1}{T_{q 0 i}^{\prime}}\left[-E_{f d i}^{\prime}-\left(X_{q i}-X_{q i}^{\prime}\right) I_{q i}\right] \\
E_{q i}^{\prime}=V_{i} \cos \left(\delta_{i}-\theta_{i}\right)+R_{s i} I_{q i}+X_{d i}^{\prime} I_{d i} \\
E_{d i}^{\prime}=V_{i} \sin \left(\delta_{i}-\theta_{i}\right)+R_{s i} I_{d i}+X_{q i}^{\prime} I_{q i}
\end{gathered}
$$

where $i=1,2,3 \ldots \ldots n, \delta_{i}$ and $w_{i}$ are the angular position and speed of rotor respectively, $w_{s}$ is the synchronous speed, $M_{i}$ and $D_{i}$ are inertia and damping constants for the machine $I$ respectively, $E_{d i}^{\prime}, I_{d i}, T_{d o i}^{\prime}$ and $X_{d i}$ represent the transient voltage, current, open circuit time constant and transient reactance respectively in d-axis, and $E_{q i}^{\prime}, I_{q i}, T_{q o i}^{\prime}$ and $X_{q i}$ represent the transient voltage, current, open circuit time constant and transient reactance respectively in q-axis. $P_{m i}$ is the mechanical input power for machine $i$, with a constant value, $V_{i}$ is the terminal voltage of the machine $i, \theta_{i}$ is its angle, and $R_{s i}$ is the armature resistance for the machine $i$.

\section{B. Automatic Voltage Regulator}

The model of the automatic voltage regulator (AVR) used in this paper is the simplified IEEE model 1, for the excitation system, its mathematical expression is [15]:

$$
\begin{gathered}
\frac{d V_{r i}}{d t}=\frac{1}{T_{a i}}\left[-V_{r i}+K_{a i}\left(V_{r e f i}-V_{i}-V_{f i}\right)\right] \\
\frac{d E_{f d i}}{d t}=\frac{1}{T_{a i}}\left[V_{r i}+\left(1+S_{e i}\left(E_{f d i}\right)\right) E_{f d i}\right] \\
\frac{d V_{f i}}{d t}=\frac{1}{T_{f i}}\left[-V_{f i}-\frac{\left(1+S_{e i}\left(E_{f d i}\right)\right) K_{f i} E_{f i}+K_{f i} V_{r i}}{T_{e i}}\right]
\end{gathered}
$$

The exciter saturation function is defined as:

$$
S_{e}\left(E_{f d}\right)=A_{e}\left(e^{B_{e}\left|E_{f d}\right|}-1\right)
$$

where $i=1,2, \ldots n, V_{\text {ref }}$ is the reference voltage of the AVR, $V_{r}, V_{f}$, and $E_{f d}$ are the excitation system stabilizer and the voltage applied to the synchronous generator field winding, while $T_{a i}, T_{e i}$ and $T_{f i}$ are the AVR, exciter and excitation system stabilizer time constants. $K a$ and $K_{f}$ are the gains of AVR. $V_{r \min }$ and $V_{r \max }$ are the lower and upper limits of $V_{r}$ and $A_{e}$ and $B_{e}$ are constants chosen to match the open circuit magnetization curve at two points.

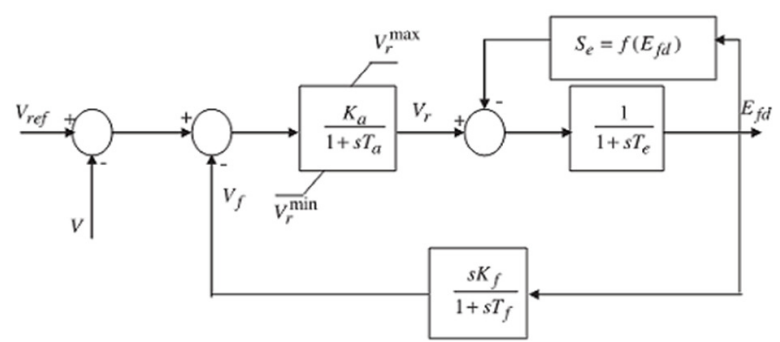

Fig. 1. Simplified IEEE model of AVR

\section{Modeling of the PV Panel}

The PV system model used in this paper is a single diode equivalent circuit described by an exponential equation $[7,16$, 17]:

$$
i=I_{s c}-I_{0}\left(e^{\frac{v+i \cdot R_{S}}{n_{S}} \cdot V_{T}}-1\right)
$$

where $I_{s c}$ and $I_{0}$ are the short circuit and open circuit currents, $R_{s}$ and $n_{s}$ are the cell series resistance and the number of cells in the panel connected in series respectively, $V_{T}$ is the junction thermal voltage including the diode quality factor, the Boltzman's constant, the temperature initial condition and the charge of the electron.

The following parameters characterize a solar cell: The short circuit current $I_{s c}$, the open circuit voltage $V_{o c}$ and the maximum power point $P_{\max }$. The fill factor $F F$ can be taken from the manufactures' datasheet where $P_{\max }=F F . V_{o c} . I_{s c}$ under nonstandard conditions. The functions of $V_{o c}$ and $I_{s c}$ depend on the absolute temperature difference $\Delta T=T_{c}-T_{a}$, where $T_{c}$ and $T_{a}$ are cell and ambient temperatures, with temperature coefficients (correction coefficients for voltage $\beta$ and correction coefficient for current $\alpha$ ) that provide the rate of change with temperature of the PV performance parameters. $I_{s c}$ and $V_{o c}$ can be represented as follows:

$$
\begin{gathered}
I_{s c}=I_{s c 25^{0}}(1+\alpha . \Delta T) \\
V_{o c}=V_{o c 25^{0}}(1+\beta . \Delta T)
\end{gathered}
$$

The irradiance variation $G_{a}$ is also required to compute the short circuit current:

$$
I_{s c}=I_{s c 25^{\circ}}\left(G_{a} / 1000\right)
$$

The voltage and current of a solar panel string depending on irradiance and temperature is expressed as:

$$
\begin{gathered}
v=n_{s e r} V_{o c}+n_{s e r} n_{s} \ln \left(1-i /\left(n_{p a r} I_{s c 25^{0}} G_{a} / 1000\right)\right) \\
v=n_{p a r} I_{s c}\left(1-e^{\left(v-n_{p a r} V_{o c}+R_{s} i\right) /\left(n_{s e r} n_{s} v\right)}\right)
\end{gathered}
$$

where $n_{s e r}, n_{\text {par }}$, and $n_{s}$ are the number panels in series, the number of strings in parallel, and the number of cells in the panel connected in series respectively.

The model is simulated in NEPLAN using the equations (14) and (15) for a single PV cell. The PV plant consists of a large number of PV modules connected in series-parallel combinations to attain the desired power level, and it is connected to the system by an aggregated DC to AC inverter. In this work, 10 cells were connected in series forming an 
array, 76806 branches were connected in parallel to form a PV plant rated at $61 \mathrm{MW}$. The short circuit current $I_{s c}$ of the cell is $3.8 \mathrm{~A}$, the open circuit voltage $V_{o c}$ of the cell is $21.1 \mathrm{~V}$, and the peak power voltage $V_{p p}$ and the peak power current $I_{p p}$ are 20.9 $\mathrm{V}$ and 3.8A respectively. The temperature was estimated at $25^{\circ} \mathrm{C}$, the irradiation was $1 \mathrm{kw} / \mathrm{m}^{2}$, and the short circuit coefficient of current $\alpha$ was $0.0036 \mathrm{I} /{ }^{\circ} \mathrm{C}$. The open circuit coefficient of voltage $\beta$ was $0.042 \mathrm{~V} /{ }^{\circ} \mathrm{C}$.

\section{STATCOM Model}

STATCOM is represented by a synchronous voltage source with maximum and minimum voltage amplitude limits. It is formed by a transformer associated with a Voltage Source Converter (VSC) that has as input a DC voltage signal and a voltage output. The transformer reactance has a small value due to the reactors and the magnetic coupling. The output parameters can be varied to control specific variables of the power system at the point of connection. The equivalent circuit is shown in Figure 2 [18].

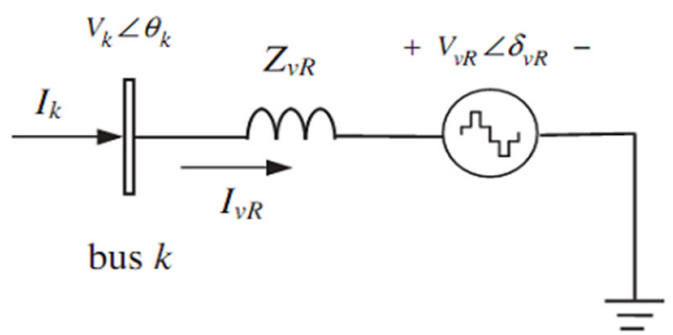

Fig. 2. Static compensator (STATCOM) equivalent circuit

The STATCOM model can be given by a source coupled in parallel to the node through an impedance in series $Y_{v r}=G_{v r}+j B_{v r}$, when the current supplied to the connected node is:

$$
I_{v r}=Y_{v r} E_{v r}-Y_{v r} V_{k}
$$

In addition, the reactive power is represented as:

$$
\begin{gathered}
Q_{v r}=V_{v R}^{2} B_{v r}-V_{v R} V_{k}\left[G_{v R} \cos \left(\delta_{v R}-\theta_{k}\right) \ldots\right. \\
\left.-B_{v R} \sin \left(\delta_{v R}-\theta_{k}\right)\right]
\end{gathered}
$$

where $\delta_{v R}$ and $\theta_{k}$ are the voltage phase angles. The controller in which the STATCOM generates or consumes reactive power is shown in Figure 3.

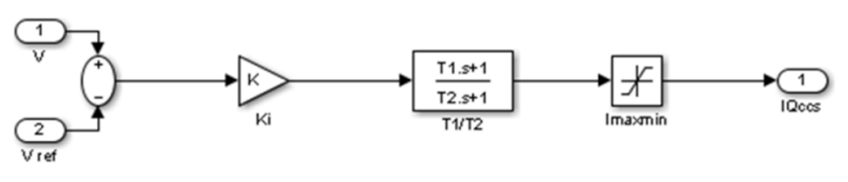

Fig. 3. Block diagram of the controller of STATCOM

\section{POWER SYSTEM IMPLEMENTATION IN NEPLAN}

The Algerian south-eastern electric network was used as a case study for transient stability. The system has two synchronous generators of thermal type, two power transformers and seven well connected fixed impedance loads as shown in Figure 4. This type of load increases transient stability more than the fixed power or the fixed current impedance loads [19]. The active and the reactive powers consumed are respectively 297.5MW and 59MVAr. The first generator is in swing mode at slack bus. The second one is in voltage control mode. In addition, a large scale generator PV, supplies $61 \mathrm{MW}$ to the power system through a PWM converter and a power transformer which are connected to bus no. 4 . The generator excitation system uses an AVR and it keeps the terminal voltage amplitude of the synchronous generator to a defined standard level. In transient state, the AVR has an important impact in maintaining voltage amplitude around the standard level during short circuits using IEEE type 1 controllers for generators' excitation. All the parameters of the test system are shown in the appendix. All loads in service are three phase in the test system and they are related to the bus voltage of $220 \mathrm{KV}$. Active and reactive power losses are respectively $7 \mathrm{MW}$ and 23.5MVAR. A significant value of the PV system could have a significant impact on the stability of the power system network. The PV parameters are discussed above. In this work, the extended Newton-Raphson method was used for power flow analysis. The number of iterations is 4 for the basic case of the test system, while in the large scale PV system with and without STATCOM, the iterations are 9 and 7 respectively. STATCOM control was used to increase transient stability and decrease voltage amplitude about $1 \mathrm{pu}$ at almost all buses of the system as shown in Figure 5.

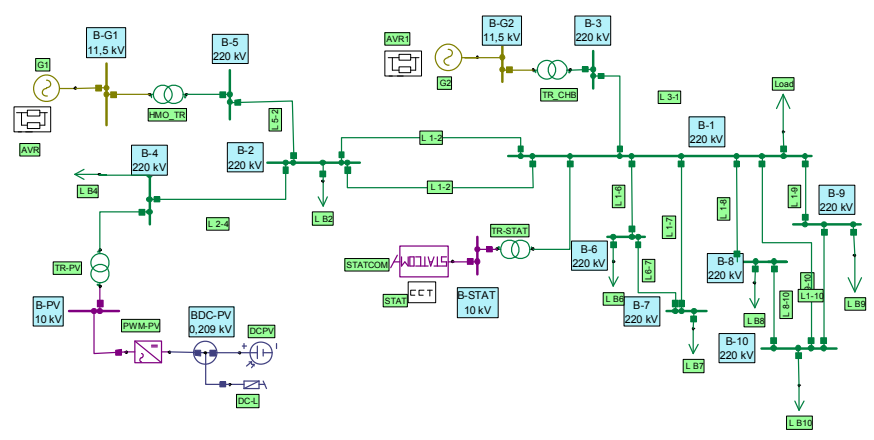

Fig. 4. Single line diagram of the test system with PV and STATCOM.

The bus B-G1 is chosen as slack bus when the synchronous generator G1 is connected. G1 will supply the balance of the real active power.

TABLE I. SIMULATION SCENARIOS FOR THE TEST SYSTEM

\begin{tabular}{|c|c|c|c|}
\hline case & Test base & PV & STATCOM with control \\
\hline (i) & Yes & No & No \\
\hline (ii) & Yes & Yes & No \\
\hline (iii) & Yes & Yes & Yes \\
\hline
\end{tabular}

The case studies are summarized in Table I. The basic load flow results of the test system bus with and without the large scale PV system are presented in Table II and Table III respectively. As seen from Tables II-IV, the amount of reactive power of $46.336 \mathrm{MVAr}$ that is generated by the system is increased to 78.244MVAr through the large scale PV generation, because the topology of the system is greater than before, and the system reactive power is reduced again to 32.488MVAr by the use of STATCOM compensator. The decrease of the reactive power generation leads to a drop in the 
overvoltage amplitude of about 1pu, when the STATCOM system absorbs a reactive power of 46.787MVAr, as shown in Figure 5 and presented in Table IV, while the power flow losses of reactive power are decreased in case (iii) as shown in Table V. So, the presence of large scale PV generation and STATCOM leads to a decrease of the overvoltage in most nodes, as compared to the basic network.

TABLE II. LOAD FLOW RESULTS IN CASE (i)

\begin{tabular}{|c|c|c|c|c|c|c|}
\hline \multirow{2}{*}{ Bus } & \multirow{2}{*}{ Type } & \multicolumn{2}{|c|}{ Voltage bus } & \multicolumn{2}{c|}{ Generation } & Injected capacitor \\
\cline { 3 - 7 } & & V (pu) & Ang (deg) & MW & MVAr & MVAr \\
\hline B-1 & PQ & 1.0314 & -10.5 & 0 & 0 & 0 \\
\hline B-10 & PQ & 1.0264 & -11.3 & 0 & 0 & 0 \\
\hline B-2 & PQ & 1.0402 & -8.7 & 0 & 0 & 0 \\
\hline B-3 & PQ & 1.0314 & -10.5 & 0 & 0 & 0 \\
\hline B-4 & PQ & 1.0413 & -8.9 & 0 & 0 & 0 \\
\hline B-5 & PQ & 1.0512 & -3.4 & 0 & 0 & 0 \\
\hline B-6 & PQ & 1.0202 & -12.4 & 0 & 0 & 0 \\
\hline B-7 & PQ & 1.0266 & -11.1 & 0 & 0 & 0 \\
\hline B-8 & PQ & 1.0257 & -11.4 & 0 & 0 & 0 \\
\hline B-9 & PQ & 1.024 & -11.7 & 0 & 0 & 0 \\
\hline B-G1 & Slack & 1.05 & 0 & 71.45 & -7.315 & 0 \\
\hline B-G2 & PV & 1.08 & 0.1 & 235 & 53.65 & 0 \\
\hline \multicolumn{7}{|c|}{ Total } \\
\hline
\end{tabular}

TABLE III. LOAD FLOW RESULTS OF CASE (ii)

\begin{tabular}{|c|c|c|c|c|c|c|}
\hline \multirow{2}{*}{ Bus } & \multirow{2}{*}{ Type } & \multicolumn{2}{|c|}{ Voltage bus } & \multicolumn{2}{c|}{ Generation } & Injected capacitor \\
\cline { 3 - 7 } & & V (pu) & Ang (deg) & MW & MVAr & MVAr \\
\hline B-1 & PQ & 1.0157 & -2.7 & 0 & 0 & 0 \\
\hline B-10 & PQ & 1.0106 & -3.6 & 0 & 0 & 0 \\
\hline B-2 & PQ & 1.0279 & -0.9 & 0 & 0 & 0 \\
\hline B-3 & PQ & 1.0157 & -2.7 & 0 & 0 & 0 \\
\hline B-4 & PQ & 1.0278 & 2.5 & 0 & 0 & 0 \\
\hline B-5 & PQ & 1.0443 & -0.4 & 0 & 0 & 0 \\
\hline B-6 & PQ & 1.0042 & -0.2 & 0 & 0 & 0 \\
\hline B-7 & PQ & 1.0108 & -3.4 & 0 & 0 & 0 \\
\hline B-8 & PQ & 1.0099 & -3.7 & 0 & 0 & 0 \\
\hline B-9 & PQ & 1.0081 & -4 & 0 & 0 & 0 \\
\hline B-G1 & Slack & 1.05 & 0 & 9.48 & 5.67 & 0 \\
\hline B-G2 & PV & 1.08 & 7.9 & 235 & 72.57 & 0 \\
\hline PV_B & PV & 1 & 3.1 & 61 & 0 & 0 \\
\hline \multicolumn{7}{|c|}{ Total } \\
\hline
\end{tabular}

TABLE IV. LOAD FLOW RESULTS OF CASE (iii)

\begin{tabular}{|c|c|c|c|c|c|c|}
\hline \multirow{2}{*}{ Bus } & \multirow{2}{*}{ Type } & \multicolumn{2}{|c|}{ Voltage bus } & \multicolumn{2}{|c|}{ Generation } & \multirow{2}{*}{$\begin{array}{c}\text { Injected capacitor } \\
\text { MVAr }\end{array}$} \\
\hline & & V (pu) & Ang (deg) & MW & MVAr & \\
\hline B-1 & PQ & 1 & -3.5 & 0 & 0 & 0 \\
\hline B-10 & PQ & 0.995 & -4.4 & 0 & 0 & 0 \\
\hline B-2 & PQ & 1.002 & -1.4 & 0 & 0 & 0 \\
\hline B-3 & PQ & 1 & -3.5 & 0 & 0 & 0 \\
\hline B-4 & PQ & 1.004 & 2.1 & 0 & 0 & 0 \\
\hline B-5 & PQ & 0.998 & -0.6 & 0 & 0 & 0 \\
\hline B-6 & PQ & 0.988 & -5.6 & 0 & 0 & 0 \\
\hline B-7 & PQ & 0.995 & -4.2 & 0 & 0 & 0 \\
\hline B-8 & PQ & 0.994 & -4.5 & 0 & 0 & 0 \\
\hline B-9 & PQ & 0.992 & -4.8 & 0 & 0 & 0 \\
\hline B-G1 & Slack & 1.05 & 0 & 9.675 & -8.976 & 0 \\
\hline B-G2 & PV & 1.08 & 7.9 & 235 & 41.464 & 0 \\
\hline B-PV & $\mathrm{PV}$ & 1 & 2.7 & 61 & 0 & 0 \\
\hline B-statcom & $\mathrm{PV}$ & 1.008 & -3.5 & 0 & 0 & -46.787 \\
\hline \multicolumn{4}{|c|}{ Total } & 305.675 & 32.488 & -46.787 \\
\hline
\end{tabular}

TABLE V. LOAD FLOW LOSSES OF THE TEST SYSTEM

\begin{tabular}{|c|c|c|}
\hline \multirow{2}{*}{ Case } & \multicolumn{2}{|c|}{ Network losses } \\
\cline { 2 - 3 } & P (MW) & Q (MVAr) \\
\hline (i) & 8.952445 & 7.336459 \\
\hline (ii) & 7.987280 & 19.243841 \\
\hline (iii) & 8.175496 & 16.696226 \\
\hline
\end{tabular}

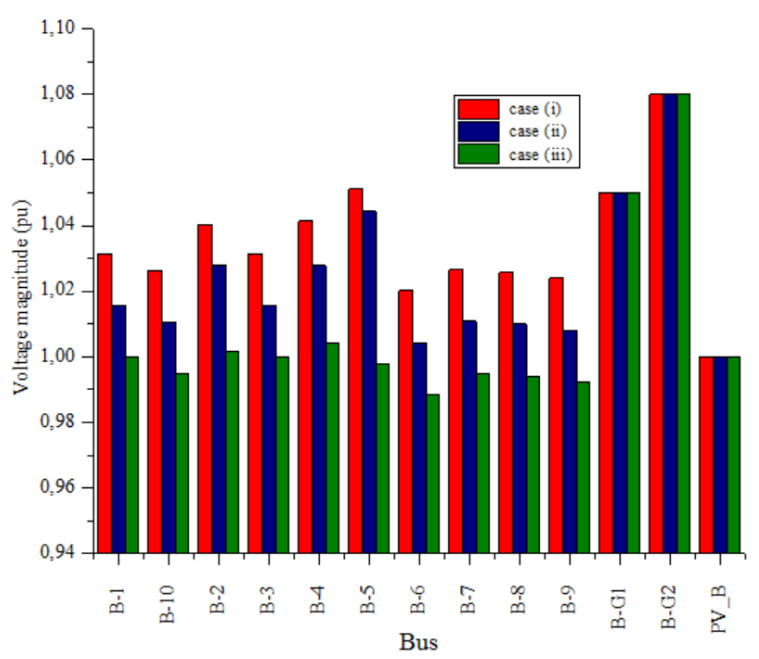

Fig. 5. Bus voltage for the three case studies

\section{Simulation RESUlts}

The 12-bus south-eastern Algerian electrical network was studied. A large scale PV generation including STATCOM is connected to the power system as shown in Figure 4. The NEPLAN software platform was used and the power network was modeled as a set of algebraic and differential equations, using the results of power flow studies as initial conditions. The differential equations were solved by numerical integration. Comprehensive simulation studies based on observed network terminal voltages, generator's rotor angles and generator's speed have been carried out. These simulations aimed at analyzing the impact of STATCOM and PV on power system transient stability. The STATCOM controls the current in order to deal with the reactive power, since the voltage at the connection point is significant for calculating control variables. The large scale PV system produces a power of $61 \mathrm{MW}$ and it is connected at bus B-4. A large disturbance occurs as a sudden short circuit at buses B-1 or B-2 which at $1 \mathrm{~s}$ with line outages $1-9$ and 1-2 respectively at $1.2 \mathrm{~s}$, while the simulation time is 20s. During the fault, it is assumed that the PV operates at its rated capacity with unity power factor.

\section{A. $1^{\text {st }}$ Scenario: Contingency at Bus 1 (Outage Line 1-9)}

In Figures 6 to 15, the behavior of the system is presented for the transient state assuming three network topologies: test base (case (i)), test base with large scale PV generation (case (ii)), and test base with PV and STATCOM (case (iii)). The benefits and the contribution of the PV and STATCOM to the test system can be seen. In Figure 6, the voltage amplitude at the node where the fault is subjected is reduced as shown in case (iii), and remains to a constant value as before the fault occurrence. The short circuit involved a voltage drop to zero during a contingency, and the return to $1 \mathrm{pu}$ after fault clearing 
for case (iii) and to 1.02 and $1.0359 \mathrm{pu}$ for cases (i) and (ii) with some oscillations at the fault clearing time. It is clearly indicated in Table IV, that the STATCOM absorbs 46.787MVAr reactive power in order to decrease the overvoltage toward the unity value. Consequently, the results of the fault are reflected in the other buses. However, the STATCOM has a high ability to absorb some reactive power since the voltage bus has a higher amplitude level.

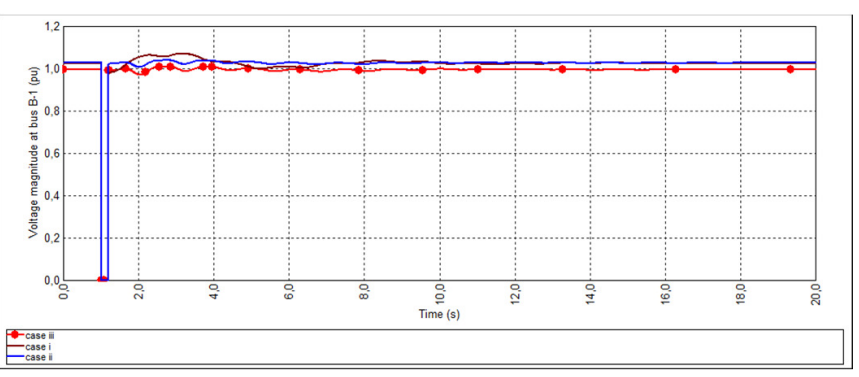

Fig. 6. Voltage amplitude at faulted bus

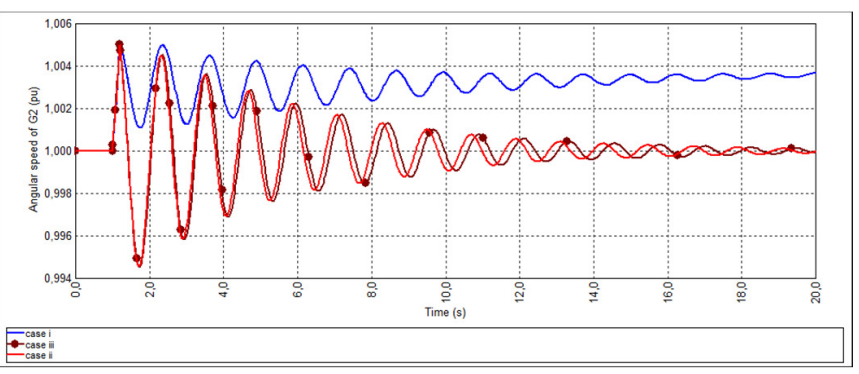

Fig. 7. Angular speed generator $\mathrm{G} 2$

Figure 7 shows the angular speed of generator $\mathrm{G} 2$ for each of the three cases. In case (i), when a disturbance occurs, an increase in the frequency from $50 \mathrm{~Hz}$ to $50.25 \mathrm{~Hz}$ for the first peak oscillation and damping to $50.175 \mathrm{~Hz}$ is noticed. In cases (ii) and (iii), the frequency returns to its initial value with some damped oscillations. The oscillation in case (iii) is lower than in case (i) or (ii). The frequency variation is presented in Figure 8 , where the first oscillation increases to $50.30 \mathrm{~Hz}$, then it drops to $50.175 \mathrm{~Hz}$ for case (i). In cases (ii) and (iii), we can see that the oscillations are the lowest, because the active power generated by generator G1 is weakest (slack generator), when a large scale PV generation is connected and a disturbance bus is longer to generator G1 and PV generation. Figure 9 presents the active power source for the three cases, including the disturbance. Active power oscillation in cases (ii) and (iii) is smaller than in case (i), after the fault clearing by opening lines $1-9$, as a short period of unbalanced condition between the mechanical input and the electrical output of synchronous generators subjected to the smaller accelerating power. On the other hand, when the PV is installed, it takes longer to recover the active power after the fault clearing. It is observed that the active power generated by PV leads to the reduction of the active power generated by slack generator G1. The rotor angle reference of generator $\mathrm{G} 2$ has a lower value and smaller oscillation peak in case (i) than in cases (ii) and (iii), because the topology of the system is changed as shown in Figure 10.

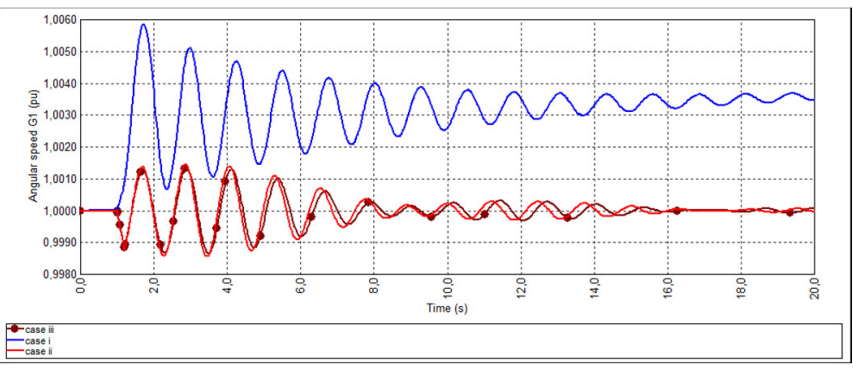

Fig. 8. Angular speed of generator G1

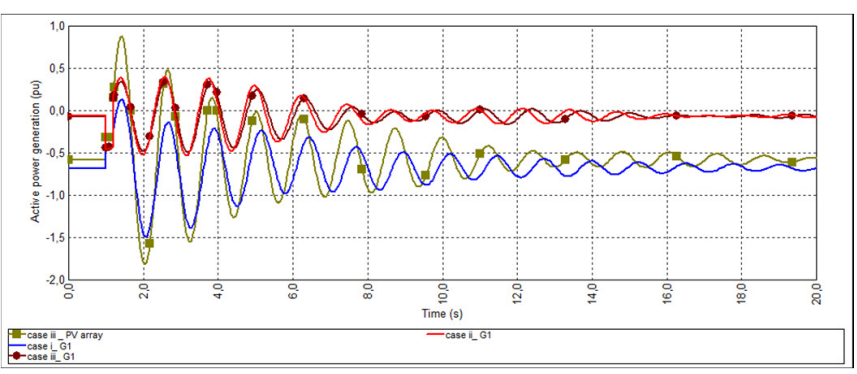

Fig. 9. Active power generation

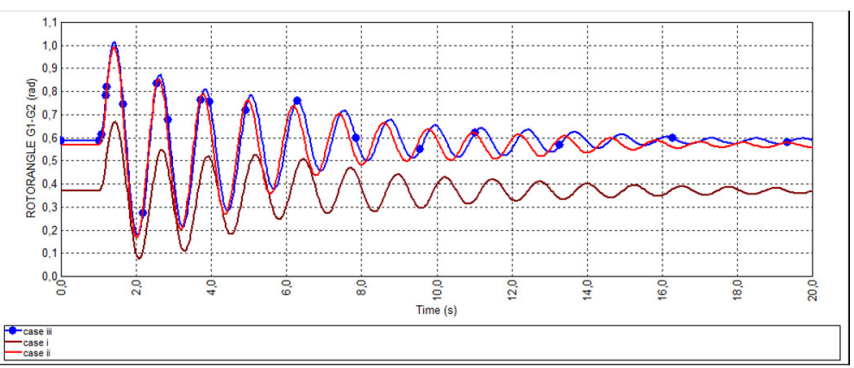

Fig. 10. Rotor angular generators

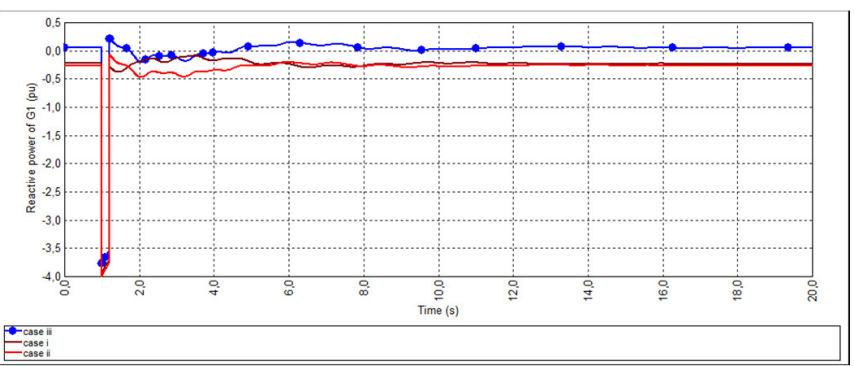

Fig. 11. Reactive power of slack generator

Figure 11 depicts the reactive power request in the power system. Reactive power is supplied by G1 to the system when its voltage amplitude is higher than $1 \mathrm{pu}$ in cases (i) and (ii), but in case (iii) the reactive power is absorbed by the STATCOM to decrease the overvoltage. Figures 12 and 13 display the comparison of active power at G1 and G2 for cases (i) and (ii) 
respectively. Therefore, for the slack generator, the active power is reduced from $0.68 \mathrm{pu}$ to $0.06 \mathrm{pu}$ when a large scale PV is installed with some damped oscillations after the disturbance. The active power of G2 is the same before the disturbance and the oscillation is reduced in case (ii) after the disturbance. In case (i), the oscillation of the active power is dropped by about $60 \%$ with respect to the first peak oscillation, and then it is damped to a stable value.

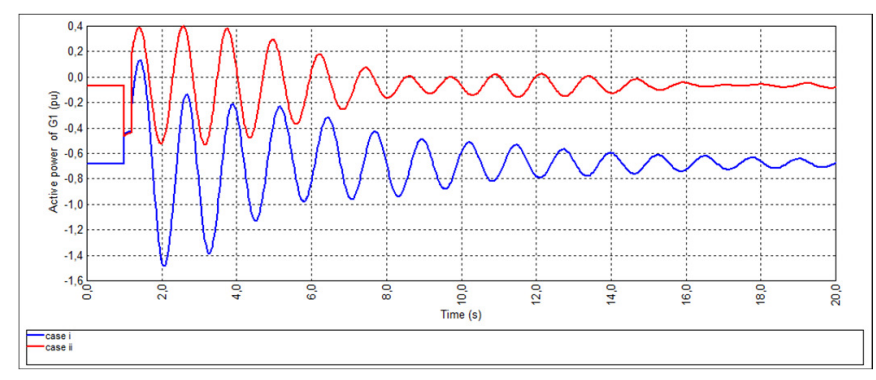

Fig. 12. Active power generation of G1

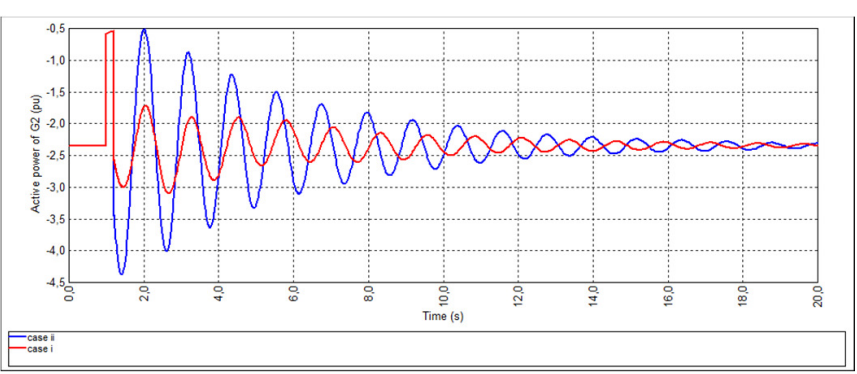

Fig. 13. Active power generation of $\mathrm{G} 2$

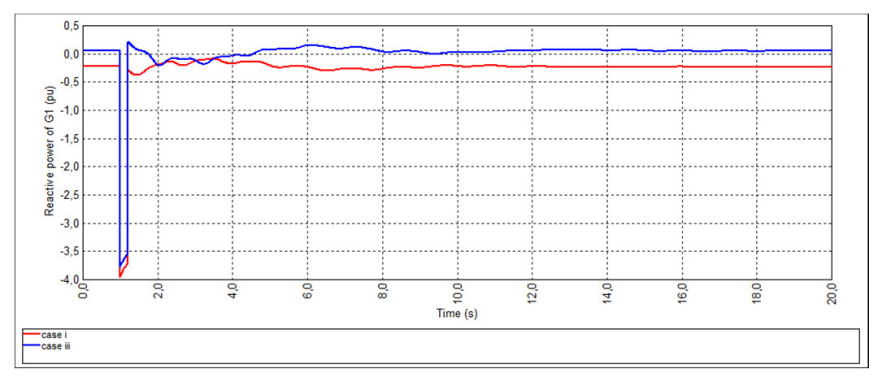

Fig. 14. Reactive power of slack generator

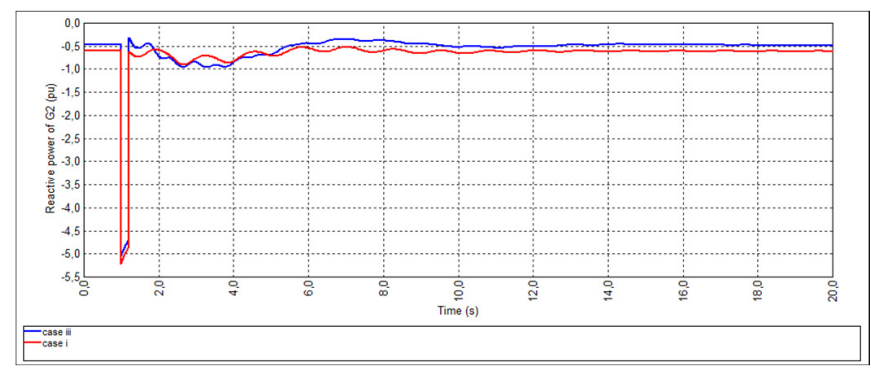

Fig. 15. Reactive power generation of G2

Figures 14 and 15 show the reactive power of G1 and G2 respectively in order to analyze the difference between case (i) and case (iii). The generator G1 supplies the reactive energy in case (i) and absorbs some reactive energy when the STATCOM is installed with some oscillations and the disturbance is cleared. For generator G2, the generated reactive power is slightly decreased with some oscillations after the disturbance.

\section{B. $2^{\text {nd }}$ Scenario: Contingency at Bus 2 (Outage Line 1-2)}

A contingency will be applied at bus 2 at $1 \mathrm{sec}$ and will be eliminated by outage in the line 1-2 at $1.2 \mathrm{sec}$. Figure 16 shows the evolution of the generator G2 relative angle which exhibits a significant oscillation when the contingency is applied. The presence of STATCOM reduces the oscillation degree and leads towards a state of stability and the fault is eliminated by line 1-2 outage. Figure 17 shows the voltage evolution at bus 2 for two contingencies applied independently. It is observed that during a fault the voltage amplitude of bus 2 is reduced to $0.556 \mathrm{pu}$ when the contingency is at bus 1 , but it becomes $0 \mathrm{pu}$ when the fault is at bus 2. Thus, the presence of STATCOM lowers the voltage level towards its nominal value.

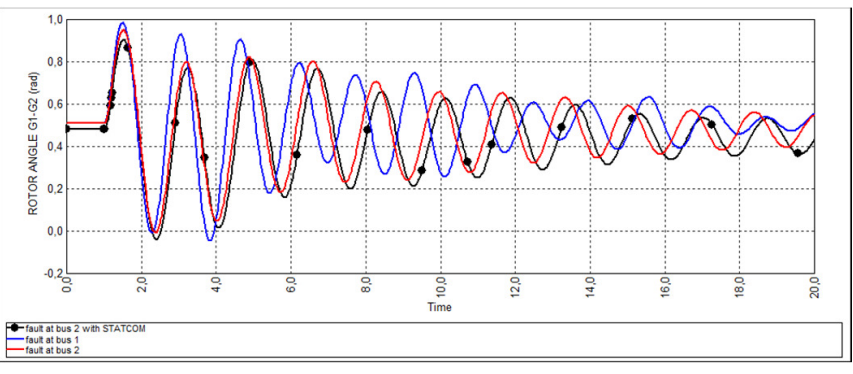

Fig. 16. Rotor G1-G2 angles

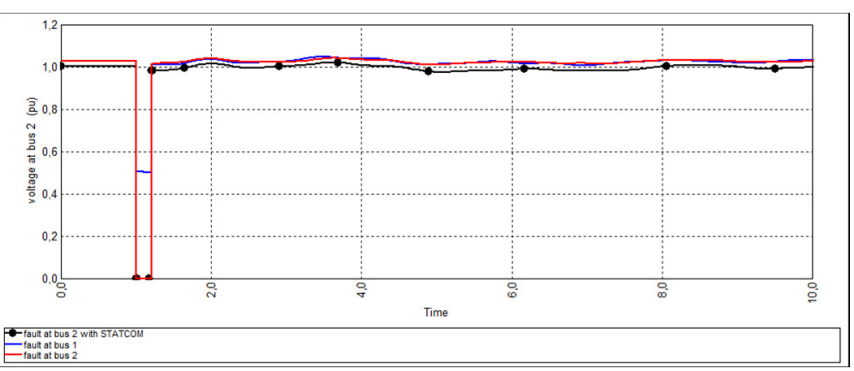

Fig. 17. Voltage amplitude at bus 2

Figures 18-19 show the supplied active and reactive power absorbed by the PV inverter and its current respectively. It can be seen that the voltage is adjusted to its reference value before and after the faults of the PV inverter. Also, a slow fluctuation of reactive power after line outage by the fault at bus 2 can be noted. Therefore, the inverter plays the role of a reactive power compensator. The presence of STATCOM gives a low reduction of reactive power during faults. These results have the same principle as those cited in [6], which shows that the inverter absorbs reactive energy if the grid voltage is greater than the nominal reference value. In Figure 19, the evolution of direct and quadratic current has negative value, so the inverter supplying active power acts and absorbs reactive power. 


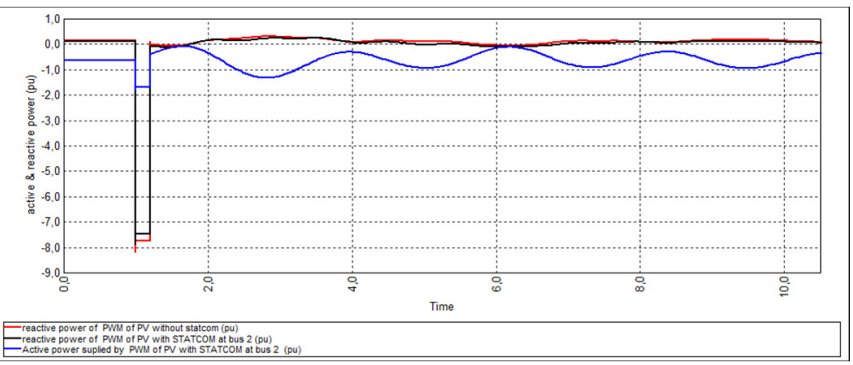

Fig. 18. Active and reactive power of PV-PWM

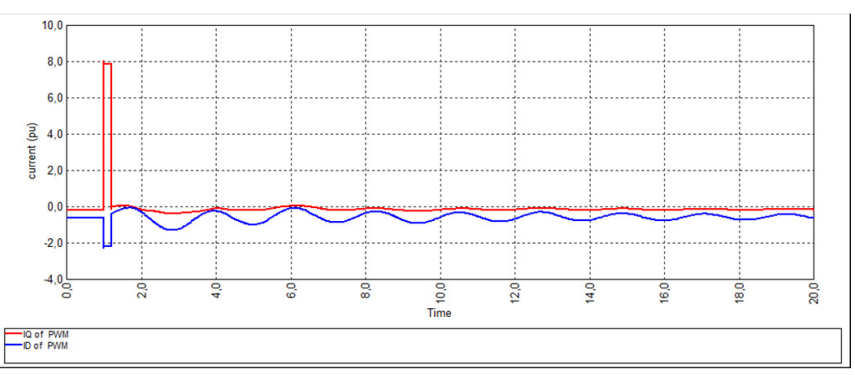

Fig. 19. Current of PWM

\section{CONCLUSION}

This paper focused on the reduction techniques of the overvoltage system buses and the assessment of the impact of a large scale PV power source on the transient stability of conventional synchronous generators in the Algerian electrical network including a STATCOM compensator. Simulations have been carried with NEPLAN. A comparison between the results of three case studies was carried out. The effect of the disturbance on the power system power was investigated for two different scenarios and three cases. In case (i), the voltage amplitude of all buses were more than $1 \mathrm{pu}$ either before or after fault disturbance. The reactive power losses were high and the test system became weak. In case (ii), it was noticed that the buses voltage amplitude exceeded the desired value and it was lower than case (i). Reactive power losses were higher than in case (i) since the PV inverter also uses reactive power and the network topology was changed. However, in case (iii), all bus voltage amplitudes near the bus in which the STATCOM was connected decreased to $1 \mathrm{pu}$. The reactive power losses were reduced significantly compared to those in cases (i) and (ii). Consequently, STATCOM had an important impact on reducing bus overvoltage and minimizing reactive power losses in a system including large PV generation with fault disturbance. The PV inverter was kept at its nominal voltage despite the fact that the imposed voltage was greater than the reference voltage, so it improved system stability.

\section{APPENDIX}

GENERATOR PARAMETERS

\begin{tabular}{|c|c|c|c|c|c|}
\hline Generator & Sbase $(\mathbf{M V A})$ & $\boldsymbol{V}(\mathbf{k v})$ & $\boldsymbol{r}(\mathbf{p u})$ & $\boldsymbol{x}_{\boldsymbol{l}}(\mathbf{p u})$ & $\boldsymbol{x}_{\boldsymbol{d}}(\mathbf{p u})$ \\
\hline $\mathrm{G} 1$ & 100 & 11.5 & 0 & 0.035 & 0.295 \\
\hline $\mathrm{G} 2$ & 100 & 11.5 & 0 & 0.0304 & 0.2495 \\
\hline
\end{tabular}

\begin{tabular}{|c|c|c|c|c|c|c|}
\hline Generator & $\boldsymbol{x}_{q}(\mathbf{p u})$ & $\boldsymbol{x}_{\boldsymbol{d}^{\prime}} \mathbf{( p u )}$ & $\boldsymbol{x}_{\boldsymbol{q}}{ }^{\prime}(\mathbf{p u})$ & $\boldsymbol{T}_{\boldsymbol{d o}}{ }^{\prime}(\mathbf{s})$ & $\boldsymbol{T}_{\boldsymbol{q o}}{ }^{\prime}(\mathbf{s})$ & $\boldsymbol{H}(\mathbf{s})$ \\
\hline G1 & 0.282 & 0.0697 & 0.17 & 6.56 & 1.5 & 30.3 \\
\hline G2 & 0.237 & 0.0531 & 0.0871 & 5.7 & 1.5 & 35.8 \\
\hline
\end{tabular}

IEEE TYPE 1 EXCITER PARAMETERS

\begin{tabular}{|c|c|c|c|c|c|c|c|}
\hline $\boldsymbol{A} \boldsymbol{V} \boldsymbol{R}$ & $\boldsymbol{T R}$ & $\boldsymbol{K A}$ & $\boldsymbol{T A}$ & $\boldsymbol{V R}_{\min }$ & $\boldsymbol{V R}_{\max }$ & $\boldsymbol{K E}$ & $\boldsymbol{T E}$ \\
\hline 1 & 0.001 & 6.2 & 0.05 & -1 & 1 & -0.633 & 0.405 \\
\hline 2 & 0.001 & 5 & 0.06 & -1 & 1 & -0.0525 & 0.5 \\
\hline $\boldsymbol{A} \boldsymbol{V} \boldsymbol{R}$ & $\boldsymbol{K F}$ & $\boldsymbol{T F}$ & $\boldsymbol{E} 1$ & $\boldsymbol{S E 1}$ & $\boldsymbol{E} 2$ & $\boldsymbol{S E 2}$ \\
\hline 1 & 0.057 & 0.5 & 3.135 & 0.66 & 4.18 & 0.88 \\
\hline 2 & 0.08 & 1 & 3.135 & 0.08 & 4.18 & 0.91 \\
\hline
\end{tabular}

PV ARRAY PARAMETERS

\begin{tabular}{|c|c|c|c|c|c|c|}
\hline & $\boldsymbol{I}_{\boldsymbol{s c}}(\mathrm{A})$ & $\boldsymbol{V}_{\boldsymbol{o c}}(\mathbf{V})$ & $\boldsymbol{T}(\mathbf{d e g})$ & $\boldsymbol{G}\left(\mathbf{K w} / \mathbf{m}^{\mathbf{2}}\right)$ & $\boldsymbol{R s}(\mathbf{p u})$ & $\boldsymbol{n}$ \\
\hline $\mathrm{PV}$ & 3.8 & 21.1 & 25 & 1 & 0.007 & 1.24 \\
\hline
\end{tabular}

\begin{tabular}{|c|c|c|c|c|c|l|c|}
\hline & $\boldsymbol{\alpha}_{\boldsymbol{I s c}}\left(\mathbf{1} /{ }^{\mathbf{0}} \mathbf{C}\right)$ & $\boldsymbol{\beta} \boldsymbol{V}_{\boldsymbol{o c}}\left(\mathrm{V} /{ }^{0} \mathrm{C}\right)$ & $\boldsymbol{\Gamma}_{\boldsymbol{r e f}}\left({ }^{0} \mathrm{C}\right)$ & $\boldsymbol{V}_{\boldsymbol{p p}}(\mathrm{V})$ & $\boldsymbol{I}_{\boldsymbol{p p}}(\mathrm{A})$ & $\boldsymbol{n}_{\boldsymbol{s}}$ & $\boldsymbol{n}_{\boldsymbol{p}}$ \\
\hline $\mathrm{PV}$ & 0.0063 & 0.042 & 25 & 20.9 & 3.8 & 10 & $\begin{array}{c}7680 \\
6\end{array}$ \\
\hline
\end{tabular}

STATCOM CONTROL PARAMETERS

\begin{tabular}{|c|c|c|c|c|c|}
\hline & $\boldsymbol{K}$ & $\boldsymbol{T} \mathbf{1}$ & $\boldsymbol{T} \mathbf{2}$ & $\boldsymbol{I}_{\boldsymbol{m a x}}(\mathbf{p u})$ & $\boldsymbol{I}_{\boldsymbol{m i n}}(\mathbf{p u})$ \\
\hline STATCOM & 5 & 0.05 & 0.05 & 2.15 & -2.15 \\
\hline
\end{tabular}

\section{REFERENCES}

[1] P. Kundur, J. Paserba,V. Ajjarapu, G. Andersson, A. Bose, C. Canizares, N. Hatziargyriou, D. Hill, A. Stankovic, C. Taylor, T. Van Cutsem, V. Vittal, "Definition and classification of power system stability", IEEE Transactions on Power Systems, Vol. 19, No. 3, pp. 1387-1401, 2003

[2] E. Emini, "Transient stability of power system with synchronous generators equipped with AVR and GOV, using Neplan software", International Research Journal of Engineering and Technology, Vol. 5, No. 2, pp. 1476-1483, 2018

[3] H. Saadat, Power system analysis, Vol. 1, McGraw-Hill, 1999

[4] L. L. Grigsby, Power system stability and control, CRC Press, 3rd edition, 2012

[5] A. S. Saidi, M. B. Slimene, M. A. Khlifi, "Transient stability analysis of photovoltaic system with experimental shading effects", Engineering, Technology \& Applied Science Research, Vol. 8, No. 6, pp. 3592-3597, 2018

[6] F. L. Albuquerque, A. J. Moraes, G. C. Guimaraes, S. M. R. Sanhueza, A. R. Vaz, "Photovoltaic solar system connected to the electric power grid operating as active poer generator and reactive power compensator", CLAGTEE 2009: 8th Latin-American Congress on Electricity Generation and Transmission, Ubatuba, Brazil, October 1822, 2009

[7] Z. A. Kamaruzzaman, A. Mohamed, "Dynamic voltage stability of a distribution system with high penetration of grid-connected photovoltaic type solar generators", Journal of Electrical Systems, Vol. 12, No. 2, pp. 239-248, 2016

[8] M. Yagami, S. Ishikawa, Y. Ichinohe, K. Misawa, J. Tamura, "Transient stability analysis of power system with photovoltaic systems installed", Journal of Energy and Power Engineering, Vol. 9, pp. 896-904, 2015

[9] N. E. Akpeke, C. M. Muriithi, C. Mwaniki, "Contribution of FACTS devices to the transient stability improvement of a power system integrated with a PMSG-based wind turbine"', Engineering, Technology \& Applied Science Research, Vol. 9, No. 6, pp. 4893-4900, 2019

[10] A. Kanchanaharuthai, V. Chankong, K. A. Loparo, "Transient stability and voltage regulation in multimachine power systems vis-a-vis STATCOM and Battery Energy storage", IEEE Transactions on Power Systems, Vol. 30, No. 5, pp. 2404-2416, 2015

[11] B. Boubekeur, A. Gharbi, H. Mellah, "Application of STATCOM to increase transient stability of wind farm", American Journal of Electrical Power and Energy Systems, Vol. 2, No. 2, pp. 50-56, 2013

[12] V. Srinivasa Rao, R. Srinivasa Rao,“Optimal placement of STATCOM using two stage algorithm for enhancing power system static security", Energy Procedia, Vol. 117, pp. 575-582, 2017 
[13] D. Chatterjee, A. Ghosh, "Improvement of transient stability of power systems with STATCOM controller using trajectory sensitivity", International Journal of Electrical Power \& Energy Systems, Vol. 33, No. 3, pp. 531-539, 2011

[14] G. Shahgholian, E. Mardani, A. Fattollahi, "Impact of PSS and STATCOM devices to the dynamic performance of a multi-machine power system", Engineering, Technology \& Applied Science Research, Vol. 7, No. 6, pp. 2113-2117, 2017

[15] A. Karami, S. Z. Esmaili, "Transient stability assessment of power systems described with detailed models using neural networks", International Journal of Electrical Power \& Energy Systems, Vol. 45, No. 1, pp. 279-292, 2013

[16] Y. Kumar, V. K. Devabhaktuni, S. Vemuru, "Comparison of power system simulation tools with load flow study cases", 2015 IEEE International Conference on Electro/Information Technology, Dekalb, USA, May 21-23, 2015

[17] Y. Zong, L. Mihet-Popa, D. Kullman, A. Thavlov, O. Gehrke, H. W. Bindner, "Model predictive controller for active demand side management with PV self-consumption in an intelligent building", 2012 3rd IEEE PES Innovative Smart Grid Technologies Europe, Berlin, Germany, October 14-17, 2012

[18] E. Barrios-Martinez, C. Angeles-Camacho, "Technical comparison of FACTS controllers in parallel connection", Journal of Applied Research and Technology, Vol. 15, No. 1, pp. 36-44, 2017

[19] M. Yagami, S. Ishikawa, Y. Ichinohe, K. Misawa, J. Tamura, "Transient stability assessment of synchronous generator in power system with high-penetration photovoltaics (Part 2)", IEEE International Conference on Electrical Machines and Systems, Busan, South Korea, October 2629,2013 